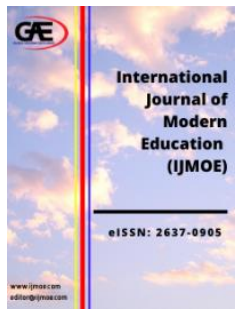

\author{
INTERNATIONAL JOURNAL OF \\ MODERN EDUCATION \\ (IJMOE) \\ www.ijmoe.com
}

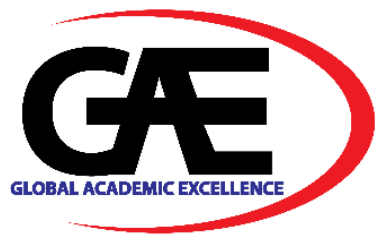

\title{
TOOLS SUPPORT E-LEARNING: A REVIEW
}

\author{
Raidah Yazid $^{1 *}$, Nur Syazwani Sukormo², Faaizah Shahbodin ${ }^{3}$, Siti Nurul Mahfuzah Mohamed ${ }^{4}$
}

1 Department of Multimedia Interactive, Universiti Teknikal Malaysia Melaka, Malaysia

Email: raidahyazid02@gmail.com

2 Department of Multimedia Interactive, Universiti Teknikal Malaysia Melaka, Malaysia

Email: syazwanisukormo@gmail.com

3 Department of Multimedia Interactive, Universiti Teknikal Malaysia Melaka, Malaysia

Email: faaizah@utem.edu.my

4 Department of Multimedia Interactive, Universiti Teknikal Malaysia Melaka, Malaysia

Email: mahfuzah@utem.edu.my

* Corresponding Author

\section{Article Info:}

\section{Article history:}

Received date: 18.07 .2021

Revised date: 30.07 .2021

Accepted date: 19.08 .2021

Published date: 05.09.2021

\section{To cite this document:}

Yazid, R., Sukormo, N. S., Shahbodin, F., \& Mohamed, S. N. M. (2021). Tools Support E-Learning: A Review. International Journal of Modern Education, 3(10), 86-93.

DOI: $10.35631 /$ IJMOE.310007

This work is licensed under CC BY 4.0

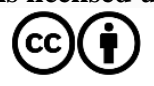

\begin{abstract}
:
Nowadays, the internet is becoming more user-centric, allowing for two-way information exchange. The term of Web 2.0 means internet applications which allow sharing and collaboration opportunities to people and help them to express themselves online. e-Learning is a term used in education to describe web 2.0 technologies and applications into educational and institutional activity. In the meantime, providing complete strategy to provide an effective learning environment that includes various courses, software, and infrastructures. Meanwhile, e-Learning is a popular method of imparting training in today's world. However, a large percentage of e-learning content fails to fulfil successful teaching and learning standards, emphasizing the need for guidelines on how to structure online resources for effective learning. Therefore, this paper has reviewed tools such a Gamification, Learning Management System (LMS), HTML-5 package (H5P) that will support elearning to develop effective learning.
\end{abstract}

\section{Keywords:}

E-Learning, Gamification, LMS, H5P

\section{Introduction}

Computers have been used for educational purposes since the 1960s and 1970s, but with the help of the Internet, they were used more enthusiastically among e-Learning volunteers, 


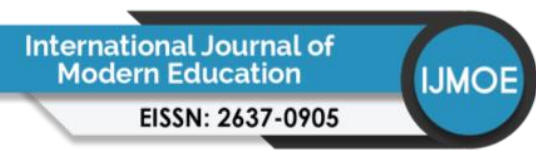

Volume 3 Issue 10 (September 2021) PP. 86-93

DOI: 10.35631/IJMOE.310007

students, and educators in 2000 (Alowayr \& Badii, 2014). Furthermore, the computer is in the second row in the efficient e-learning process in terms of providing technical improvement, either with the assistance of the latest hardware and software. Thus, technology has the potential to alter education. It can assist instructors and students develop and progress their relationships, reinvent our approach to learning and collaboration, close equity gaps, ensure long-term accessibility, and customise learning experiences to match the needs of all students (US Department of Education, 2016). Moreover, through individualized learning, technology is becoming a prominent trend in education. Students can pick what they study, how they learn, and how their learning is displayed via technology. Teachers and students can respond to vulnerabilities and enhance strengths during the learning process using formative research aided by digital resources (Mohd et al., 2020).

e-Learning is concerned with distributed learning, online learning, interactive learning, webbased or networked learning, and testing and determining the best reviews, involvement, and interaction between the teacher and the learner in e-learning environments through specific channels (Alowayr \& Badii, 2014). Three primary interactions underpin e-Learning instruction: student-student interaction, student-instructor interaction, and student-content interaction. These three interactions are the foundational relationships that make an e-learning environment run smoothly (Luo et al., 2017). Besides, e-Learning is widely employed as a new method of delivering instruction around the world. However, a large percentage of e-learning content fails to meet the criteria for effective teaching and learning, stressing the need for guidance on structuring online resources for effective learning. With that in mind, numerous tools for e-learning support have been discussed in the literature review section.

\section{Literature Review}

\section{Gamification}

Although gamification is not a fundamental aspect of adaptive learning, gamification can successfully organise and increase learning engagement (Mahfuzah Mohamad et al., 2019). Gamification plays a vital and positive role in such a complex situation. Teachers can apply game elements to non-game situations to engage pupils in problem-solving and improve their motivation and academic performance. Students who participate in games gain more intellectual ability than those who do not. According to research, this boosts their motivation and academic achievement (Antón-Rodríguez et al., 2020).

Furthermore, gamification could develop as a valuable, cost-effective, and efficient technique for educators to improve learning outcomes (Sanchez et al., 2020). Gamification is applying game design features (e.g., points) and game characteristics (e.g., assessment, challenge) to generate positive outcomes in non-game environments. Gamification is a phrase that refers to the usage of game-based concepts and practises outside of leisure activities to enhance participant motivation and enhancing results (Salen, K. and Zimmerman, 2003). Gamification has been investigated as a means of increasing motivation and engagement in educational and work-related settings (Hamari \& Sarsa, 2014). In this regard, there have been earlier examples of gamification approaches being used in both official and informal learning situations (Lee \& Hammer, 2011). 


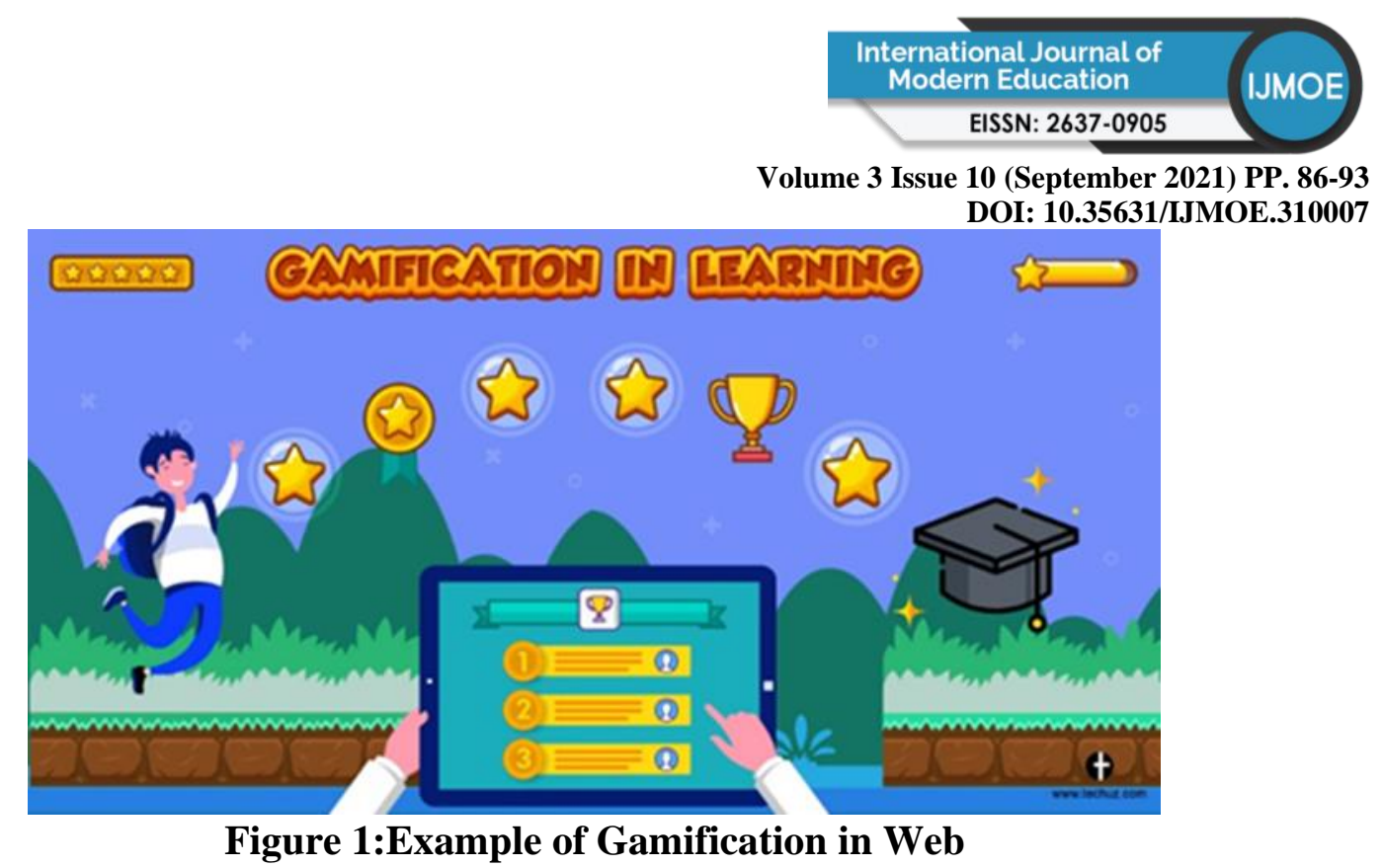

For instance, Figure 1 has illustrated the gamification in learning tools like Moodle. Poondej \& Lerdpornkulrat (2019) described the gamification planning in Moodle. These five elements of game mechanics have identified that used extensively in the learning context.

\section{Five Elements of Game Mechanics}

\section{Experience Points $(X P)$}

Students can gain XP points in two ways: when they finish the quiz, and when they perform a specific action in an e-learning course, such as checking in, posting in forums, or accessing reading materials. The quantity of XP awarded varies based on how much effort is required to complete the task.

\section{Levels}

May employs an exponential technique to dynamically calculate the level based on the XP required to get it to estimate the number of levels. There are 20 level computations in this system.

\section{Badges}

Badges are divided into two categories. To inspire students, you could establish some activities that they must perform to get a badge, such as engaging in forums, asking smart questions, and working hard; second, you might build a badge that they earn each time they fulfil a specified task.

\section{Leader Boards}

To provide a visual representation of how students in each endeavour can use the level board system at the peer level. This allows pupils to compare their progress and performance to those of their classmates.

\section{Progress Bars}

Use the progress bar to show how far students have progressed to the next level. Giving pupils feedback can help them study more effectively.

According to the LMS Industry User Research Study (Brian Westfall, 2020), gamification is the first Learning Management System (LMS).Besides, incorporating gamification elements 
Volume 3 Issue 10 (September 2021) PP. 86-93 DOI: 10.35631/IJMOE.310007

into e-Learning would also raise user motivation and engagement during the learning process and enable users to use the e-Learning for a longer time (Nurul \& Mohamad, 2018).

\section{Learning Management System}

The uses of technology in the learning process are to disseminate, illustrate, communicate, or maintain students and teachers in activities designed to sustain learning. The application of technology in learning is expected to increase the effectiveness of learning (Gunawan et al., 2019).Moodle is one of the most widely used open-source course management systems in online education right now. It is a PHP-based free and open-source learning management system published under the GNU General Public License. Moodle, based on pedagogical concepts, is used in schools, universities, workplaces, and other sectors for blended learning, remote education, flipped classroom, and other e-learning projects. It is used to develop private websites with online courses for educators and trainers to meet learning goals, and it has customised management tools. Using community-sourced plugins, Moodle (acronym for Modular Object-Oriented Dynamic Learning Environment) enables for the extension and customization of learning environments. Moodle's source code is built in PHP, a popular opensource programming language that was designed to create dynamic Web pages. The Moodle trust oversees the platform's core development, but the software is meant to be very flexible, and throughout the years, several individuals and organisations have produced plug-ins and other add-ons to expand capabilities.

\section{Strength}

- Open-Source: It is free and simple to use for teachers.

- Flexible Learning: Moodle's eLearning platform allows students to access courses and information at any time.

Learners can access materials from anywhere they have Internet access, allowing them the flexibility to learn at their own pace.

- Mobile Compatibility: Moodle provides mobile eLearning, which makes learning on the go more convenient. Mobile eLearning is viewed as a valuable addition to the learning process because it allows students to access course content from any mobile device.

- Multilingual: Moodle is available in over 100 languages, making it accessible to students all over the world. As a result, you will be able to offer your courses in as many languages as you like.

\section{Weaknesses}

- In some web browsers, you will not be able to embed stuff.

- There are no instructions or assistance on how to use specific functions.

- Without substantial code work, the interface design does not provide many possibilities for rebranding and modifying its appearance and feel.

- Many major corporate clients want a full-featured competency development and management toolkit, which Moodle lacks. Moodle suffers in certain markets where strong competency management is a must, despite workarounds that provide some competency monitoring and reporting.

Despite these drawbacks, Moodle is an excellent Learning Management System (LMS). Its concentration on simplicity makes it excellent for groups with little resources, such as schools, non-profits, small companies, and local government agencies. 


\section{Integration of H5P Activities}

DOI: 10.35631/IJMOE.310007

H5P, or HTML-5 Package, is a plugin solution that enables educators to create and run interactive content and video within a learning management system (LMS) or any e-Learning browser. H5P has the following advantages: open-source, free to use, HTML5 compliant, responsive, and accessible. The Learning Environment Team identified the open-source tool 'H5P' as a suitable tool with a large suite of interactive objects that used to present to students and engage them in a variety of activities (Lambda solution, 2020).

To support a Learning Tools Interoperability (LTI) was created to incorporate the H5P tool into the LMS, allowing academics to design their own online interactive lectures and learning activities quickly and efficiently. H5P (HTML-5 package) is a tool for creating rich interactive HTML-5 e-learning content that can be shared and reused. Several authors have emphasised the necessity of implementing interactive activities to enhance meaningful and active learning (Singh \& Scholz, 2019). Table 1 has summarized the type of interactive content of H5P.

Table 1: Type of Interactive Contents Of H5P (Lambda solution, 2020)

\begin{tabular}{|c|c|}
\hline Image & Descriptions / Functions \\
\hline & To create time-based arithmetic quizzes \\
\hline & To create text-based turning cards \\
\hline & To create a presentation with interactive slides \\
\hline & To create drag and drop tasks with images \\
\hline & To create task with missing words in a text \\
\hline & To create stylish and modern flashcards \\
\hline & To create an image with a question and answer \\
\hline
\end{tabular}




\begin{tabular}{|l|l|}
\hline Image & \multicolumn{1}{|c|}{ Descriptions / Functions } \\
\hline & To create text-based drag and drop tasks \\
\hline & To create flexible multiple-choice questions \\
\hline & To create personality quizzes \\
\hline & To create a questionnaire to receive feedback \\
\hline & To create a sequence of various question types \\
\hline
\end{tabular}

\section{Conclusion}

Students have a variety of learning styles. For example, some people learn best through graphics, while others prefer writing and reading. Others may learn through experimentation and example, while others may deal with theory. e-Learning is a step ahead of inefficiently securing future educational demands with new teaching aids. The discussion about the tools that support e-learning, such as gamification, with their element of game mechanics can give a sense of motivation and engagement. Meanwhile, Moodle is an open-source platform that sustains online learning. H5P also assisting thru a large suite of interactive objects and a variety of activities. These features of integrating or embedded with another system are the great advantage of H5P. In future planning for online education, e-learning can be developed by 


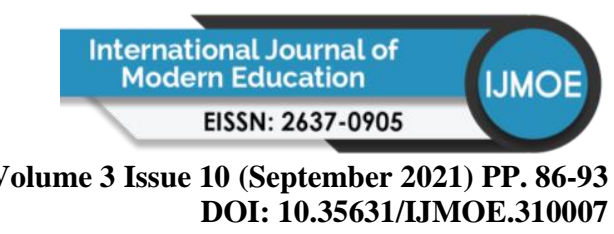

Moodle as a platform and add the activities of courses with gamification tools and H5P activities.

\section{Acknowledgement}

We would like to thank this work was supported by grant Industri (MTUN)/IPSB/2020/FTMKCACT/100044, Universiti Teknikal Malaysia Melaka (UTeM).

\section{References}

Alowayr, A., \& Badii, A. (2014). Review of Monitoring Tools for E-Learning Platforms. International Journal of Computer Science and Information Technology, 6(3), 79-86. https://doi.org/10.5121/ijcsit.2014.6306

Antón-Rodríguez, M., Pérez-Juárez, M. Á., Diáz-Pernas, F. J., González-Ortega, D., MartínezZarzuela, M., \& Aguiar-Pérez, J. M. (2020). An Experience of Game-Based Learning in Web Applications Development Courses. OpenAccess Series in Informatics, 81(3), 1-3. https://doi.org/10.4230/OASIcs.ICPEC.2020.3

Brian Westfall. (2020). The Top Learning Management System Statistics Impacting Education. https://www.capterra.com/learning-management-system-software/user-research/

Gunawan, G., Sahidu, H., Susilawati, S., Harjono, A., \& Herayanti, L. (2019). Learning Management System with Moodle to Enhance Creativity of Candidate Physics Teacher. Journal of Physics: Conference Series, 1417(1), 0-6. https://doi.org/10.1088/1742$6596 / 1417 / 1 / 012078$

Hamari, J., \& Sarsa, H. (2014). Does Gamification Work? - A Literature Review of Empirical Studies on Gamification. 3025-3034. https://doi.org/10.1109/HICSS.2014.377

Lambda solution. (2020). What is H5P? (And Why Your eLearning Needs It!). https://www.lambdasolutions.net/

Lee, J. J., \& Hammer, J. (2011). Gamification in Education: What, How, Why Bother? Academic Exchange Quarterly, 15, 146.

Luo, N., Zhang, M., \& Qi, D. (2017). Effects of different interactions on students' sense of community in e-learning environment. Computers \& Education, 115, 153-160. https://doi.org/https://doi.org/10.1016/j.compedu.2017.08.006

Mahfuzah Mohamad, S. N., Mohd Salleh, M. A., Abdul Hamid, M. H., Mei Sui, Bl. K., \& Che Ku Mohd, C. K. N. (2019). Adaptive Learning Strategies with Gamification to Enhance Learning Engagement. Indian Journal of Science and Technology, 12(31), 1-8. https://doi.org/10.17485/ijst/2019/v12i31/146871

Mohd, C. K. N. C. K., Shahbodin, F., Saad, M. S. M., Nor, A. M., Mohamad, S. N. M., \& Saaya, Z. (2020). Educational technologies in a personalised learning environment (PLE): an overview. World Transactions on Engineering and Technology Education, 18(4), 485-490.

Nurul, S., \& Mohamad, M. (2018). Gamification Approach in Education to Increase Learning Engagement. International Journal of Humanities, Arts and Social Sciences, 4(1), 22 32. https://doi.org/10.20469/ijhss.4.10003-1

Poondej, C., \& Lerdpornkulrat, T. (2019). Gamification in E-learning: A moodle implementation and its effect on student engagement and performance. Interactive Technology and Smart Education, 17(1), 56-66. https://doi.org/10.1108/ITSE-062019-0030

Salen, K. and Zimmerman, E. (2003). Rules of Play: Game Design Fundamentals. 
Volume 3 Issue 10 (September 2021) PP. 86-93 DOI: 10.35631/IJMOE.310007

Sanchez, D. R., Langer, M., \& Kaur, R. (2020). Gamification in the classroom: Examining the impact of gamified quizzes on student learning. Computers and Education, 144(August). https://doi.org/10.1016/j.compedu.2019.103666

Singh, S., \& Scholz, K. (2019). Using an e-authoring tool (H5P) to support blended learning: Librarians' experience. ASCILITE 2017 - Conference Proceedings - 34th International Conference of Innovation, Practice and Research in the Use of Educational Technologies in Tertiary Education, 158-162.

US Department of Education. (2016). Future Ready Learning. Office of Educational Technology, 1-106. 